\title{
Winter Maintenance Wash-Water Heavy Metal Removal Pilot Scale Evaluation
}

\author{
Christopher M. Miller, William H. Schneider IV, Mufuta J. Tshimanga, and Philip Custer
}

University of Akron, 244 Sumner Street, Akron, OH 44325, USA

Correspondence should be addressed to Christopher M. Miller; cmmiller@uakron.edu

Received 6 June 2016; Revised 22 August 2016; Accepted 4 September 2016

Academic Editor: Manuel A. R. Rodrigo

Copyright (C) 2016 Christopher M. Miller et al. This is an open access article distributed under the Creative Commons Attribution License, which permits unrestricted use, distribution, and reproduction in any medium, provided the original work is properly cited.

\begin{abstract}
To encourage sustainable engineering practices, departments of transportation are interested in reusing winter maintenance truck wash water as part of their brine production and future road application. Traffic-related metals in the wash water, however, could limit this option. The objective of this work was to conduct a pilot scale evaluation of heavy metal (copper, zinc, iron, and lead) removal in a filtration unit (maximum flow rate of $45 \mathrm{~L} /$ minute) containing proprietary (MAR Systems Sorbster ${ }^{\circledR}$ ) media. Three different trials were conducted and approximately 10,000 L of wash water collected from a winter maintenance facility in Ohio was treated with the pilot unit. Lab studies were also performed on six wash-water samples from multiple facilities to assess particle size removal and estimate settling time as a potential removal mechanism during wash-water storage. Pilot unit total metal removal efficiencies were 79\%, 77\%, 63\%, and 94\% for copper, zinc, iron, and lead, respectively. Particle settling calculation estimates for copper and zinc show that 10 hours in storage can also effectively reduce heavy metal concentrations in winter maintenance wash water in excess of $70 \%$. These pilot scale results show promise for reducing heavy metal concentrations to an acceptable level for reuse.
\end{abstract}

\section{Introduction}

During the winter months of the year, snow events can interfere significantly with car and truck based transportation systems. To minimize the effects of these events, the application of anti-icing, pretreatment, and deicing liquids alongside snow plowing is practiced. Anti-icing agents such as calcium acetate, magnesium acetate, and calcium chloride are occasionally applied to roadways. In Ohio, approximately $\$ 50$ million is spent on snow and ice removal annually, accounting for almost half of the annual operating budget. An average of 600,000 tons of salt is used to maintain Ohio's 43,000 lane miles each year [1]. Due to the corrosive nature of salt, trucks are washed frequently during winter months at garages across the state. At garages with sanitary sewer access, truck wash water is disposed of through the sewer system after treatment by an oil/water separator. Garages without sewer access must find an alternative method of managing truck wash water which falls in line with disposal guidelines. Alternatively, based on the concentrations of suspended solids, oil and grease, and dissolved solids in truck wash water, previous researchers have shown that truck wash water could be reused for the production of brine after a treatment process including an oil/water separator and settling tank $[2,3]$.

However, the main restrictive elements to winter maintenance wash-water reuse as brine are posed by heavy trafficrelated metals that are in violation of EPA set standards and regulations. The traffic heavy metals of concern were observed during a study of water quality parameters of wash water taken during wash cycles at 24 ODOT garages during the winter of 2012-2013. Of all samples tested, 59\% were above the reuse limitations for total copper and $66 \%$ were found to be above in total zinc [4]. Considering both metal concentrations, only $28 \%$ of all samples were found to be reusable according to the Ohio Administrative Code (OAC) aquatic, agricultural, and wildlife standards based on the characteristic hardness of receiving water bodies. The presence of heavy metals above threshold potentially creates a toxic environment, and accumulation over a prolonged period of time can harm receiving water environment by affecting the health of the aquatic ecosystem [5]. Many heavy metals, especially lead and zinc, have been recognized as traffic-related pollutants [6-8]. Specific sources of heavy metals include tire treads for which zinc oxide is an activator during the vulcanizing 
process, resulting in a composition of between $0.4 \%$ and $4.3 \%$ [9]. Other heavy metals in tire tread include manganese, iron, cobalt, nickel, copper, zinc, cadmium, and lead [10]. Brake dust has been recognized as a significant pollutant for copper, antimony, and barium [11]. 47\% of the total loading for copper in urban runoff is also contributed by brake dust [12]. Additional sources of heavy metals in urban areas include corrosion of buildings and their fittings, atmospheric deposition, transport, and other industrial activities [12, 13]. Most heavy metals in urban storm water runoff are attached to suspended solids $[6,14]$ with metal concentrations generally increasing with decreasing particle size $[15,16]$ due to the relatively large surface area of fine sediments and higher exchange capacity [6]. Furthermore, particles smaller than $50 \mu \mathrm{m}$ can be a significant component in runoff, contributing to as much as three-quarters of the weight of total solids [17].

The treatment of contaminants in wash water can be achieved using various conventional and emerging methods including ion exchange, electrolyte or liquid extraction, precipitation, and reverse osmosis [18]. However, most of the physiochemical techniques are either economically unfavorable [19] or simply too technically complicated. As an alternative, other studies investigated the removal of storm water contaminants through different media such as calcite, zeolite, iron fillings, and sand through column and batch experiments $[20,21]$. These studies found that no single filter medium was capable of removing all contaminants.

There are few options for removing heavy metals in wash water which include the aforementioned physiochemical techniques. For application at DOT garages, there is a need for any technology selected to be simple to use, to be costeffective, and to require low maintenance, thus negating the options listed above. Therefore, there is a need for pilot evaluation of media particular to traffic-related heavy metals which allows for heavy metal removal from DOT garage wash water. This study investigates the efficiency of MAR Sorbster media, proprietary media for the removal of heavy trafficrelated metals (copper, zinc, lead, and iron) from winter maintenance wash water. Experiments were conducted on the MAR Sorbster media testing metal removal efficiency using wash water from actual maintenance events as well as spiked wash water synthesized using actual winter maintenance wash water. The experiments and gradation examinations allowed insights to be made regarding removal efficiency of the traffic-related heavy metals in addition to the effects of particles size distribution of traffic-related heavy metals.

\section{Materials and Methods}

2.1. Filtration Unit. The filtration unit consisted of two 1,136liter vessels in series with a continuous downflow configuration. A pair of $5 \mu \mathrm{m}$ filters was installed immediately after the inlet of the filtration pilot unit but prior to the inlet of the vessels. These filters were arranged in a parallel configuration with the water entering the filtration unit split by a splitter so that it can be treated by either one of the filters. At the outlet of the vessels, a pair of $1 \mu \mathrm{m}$ filters was installed in a parallel configuration as well. The filters help reduce the amount of suspended solids in the wash water entering the filtration pilot unit as well as in the effluent of treated wash water, improving the life of the media. The wash water was pushed through the filtration pilot unit using a model MCS close coupled, end suction, centrifugal pump with a threaded shaft extension.

2.2. Filter Media. MAR Sorbster media were selected for this study following a series of batch experiments with four different media types in which MAR Sorbster had the most efficient heavy metal removal characteristics [4]. MAR Sorbster is a proprietary medium that removes metal contaminants from water. It is an enriched alumina medium. Each vessel was filled with $102 \mathrm{~kg}$ of gravel constituting the bottom layer and $495 \mathrm{~kg}$ of MAR Sorbster media as the overlying layer. The moisture content of the media was $<10 \%$. The physical properties of the media were obtained from the manufacturer. The specific gravity was 3-4. The grain size of the MAR Sorbster media was $0.0048 \mathrm{~m}$ which was assumed to be uniform. The physical state of the media was as free flowing granules. Before use on the wash water, the media were dry loaded into the pilot unit and then backwashed at a flow rate of 35-45 L/minute which resulted in a bed expansion of approximately $15 \%$. Backwashing was done to avoid plugging of the media by any debris as well as reduce the amount of total suspended solids in the treated wash water through particulates in the media and gravel. In between experimental runs, the media were kept in a damp state in order to maintain an optimal removal state. The hydraulic time was controlled through the flow rate. The optimal contact time for heavy metal removal by the MAR Sorbster media is 30 minutes. The flow rate was adjusted to $38 \mathrm{~L} /$ minute such that the contact time in each vessel was 15 minutes.

2.3. Wash-Water Pilot Testing Procedures. Wash water for all experimental runs was collected from the oil/water separator at the Stark County garage in Canton, Ohio, and pumped directly from the swap truck using a sump pump into the filtration unit. To observe the variability and characteristics of the wash water, a 3-hour wash cycle study was conducted at the Stark County garage oil/water separator in Canton, Ohio. During this 3-hour study, samples were collected every 15 minutes at a consistent depth below the oil layer. Each sample was placed in $0.5 \mathrm{~L}$ high density polyethylene bottle; $125 \mathrm{~mL}$ of the sample was preserved with $(1+1)$ reagent grade nitric acid at $\mathrm{pH}<2$. The rest of the sample was left unpreserved. During this study, particles below $5 \mu \mathrm{m}$ in diameter were assumed to be in the dissolved state. The individual average values of the nonmetal parameters for the wash water were measured using a minimum of 9 samples from different time intervals. Three experimental runs were conducted on the MAR Sorbster media. Stark 1, the first trial, was a 3,255 L run of wash water. Stark 2, the second trial, was a 2,650 L run of wash water spiked with 1.92 grams of $\mathrm{CuSO}_{4} \cdot 5 \mathrm{H}_{2} \mathrm{O}$, 2.03 grams of $\mathrm{ZnO}$, and 3.99 grams of $\mathrm{PbCO}_{3}$. Stark 3, the third trial, was a $4,164 \mathrm{~L}$ run of wash water spiked with 1.82 grams of $\mathrm{CuSO}_{4} \cdot 5 \mathrm{H}_{2} \mathrm{O}, 3.35$ grams of $\mathrm{ZnO}$, and 3.98 grams of $\mathrm{PbCO}_{3}$. Stark 2 and Stark 3 were spiked in order to elevate the concentration of dissolved target metals in the untreated wash water to assess the removal capabilities of the media with higher concentrations of dissolved metals. 
During each experimental run, samples were taken at the following locations on the pilot unit: influent $\left(C_{o}\right)$, after the $5 \mu \mathrm{m}$ filters, after the first filtration unit vessel, after the second filtration unit vessel, and after the $1 \mu \mathrm{m}$ filters $\left(C_{e}\right)$. For Stark 2 and Stark 3, the $1 \mu \mathrm{m}$ filters were removed which effectively made the effluent the same as the location after the second pilot unit vessel. Samples were collected every 15 minutes, characteristic of the water-to-media contact time for a single filtration unit vessel. Each sample was placed in $0.5 \mathrm{~L}$ high density polyethylene bottle; $125 \mathrm{~mL}$ of the sample was preserved with $(1+1)$ reagent grade nitric acid at $\mathrm{pH}$ $<2$. The difference between the influent and the effluent concentrations was used to calculate the percent removal by the media. The equation is listed below:

$$
\text { heavy metal removal }(\%)=\frac{\left(C_{o}-C_{e}\right)}{C_{o}} \times 100 \text {, }
$$

where heavy metal removal signifies the amount of heavy metals removed from the wash water by the MAR Sorbster media. $C_{e}$ is the average concentration of the effluent and $C_{o}$ is the average concentration of the influent.

In order to assess the proportion of the particles greater than $4 \mu \mathrm{m}$ contributing to the total metal concentration, a Whatman filter paper procedure was used. Five ODOT county garages, namely, Allen, Stark, Fairfield, Guernsey, and Cuyahoga county garages, were selected for sampling using the same samples that were initially collected for the washwater analysis. These garages were selected because they represented garages at which the metals of concern exceeded reuse limits consistently during the previous study in the 24 ODOT garages which was conducted in the winter of 20122013 [4]. Three size fractions were selected, $<4 \mu \mathrm{m}, 4 \mu \mathrm{m}<$ size $<5 \mu \mathrm{m}$, and $>5 \mu \mathrm{m}$. The wash-water samples from the six garages were separated into three size fractions using $4 \mu \mathrm{m}$ and $5 \mu \mathrm{m}$ filter paper. Each sample was placed in $0.5 \mathrm{~L}$ high density polyethylene bottle; $125 \mathrm{~mL}$ of the sample was preserved with $(1+1)$ reagent grade nitric acid at $\mathrm{pH}<2$. This procedure analyzed the dissolved metal concentration, the total metal concentration, and concentration between $4 \mu \mathrm{m}$ and $5 \mu \mathrm{m}$. The fractions of each size fraction's contribution to the total metal concentration were used to assess settling as a viable option to total metal concentration reduction in ODOT winter maintenance wash water.

2.4. Settling Calculations. Settling could be a crucial mechanism in heavy metal removal. Settling rates are dependent on several different variables. The primary variables are the physical properties of both the settling particle and the fluid in which the particle is settling. The behavior of the fluid is related to two intrinsic properties of the fluid: density and viscosity. The density of a fluid is its mass per unit volume. The density of a fluid is affected by changes in temperature and pressure. The viscosity of a fluid is the measure of the internal resistance. The viscosity of Newtonian fluids is affected by temperature, pressure, and, in the case of solutions and mixtures, composition. For the case of this study, it will be assumed that pressure will remain constant at atmospheric pressure. The composition of winter maintenance wash water varies greatly based on the characteristics of the roadways being maintained. Of the variances, salinity would have the greatest effect on the settling times of particles.

Settling calculations were conducted for various sized particles of the metals copper, zinc, lead, and iron. Equation (2), Stokes law, was used to calculate the settling velocity for the above stated metals. Stokes equation is listed below:

$$
V_{s}=\frac{g d^{2}\left(\rho_{p}-\rho_{m}\right)}{18 \mu}
$$

where $V_{s}$ is the settling velocity, $g$ is the acceleration due to gravity, $d$ is the diameter of particle, $\rho_{p}$ is the density of particle, $\rho_{m}$ is the density of medium, and $\mu$ is the dynamic viscosity. The acceleration due to gravity was assumed to be $9.81 \mathrm{~m} / \mathrm{s}^{2}$, and the diameter of the particles ranged from $1 \mu \mathrm{m}$ to $5 \mu \mathrm{m}$ in $1 \mu \mathrm{m}$ increments. The density of copper was $8,960 \mathrm{~kg} / \mathrm{m}^{3}$, of zinc was $7,140 \mathrm{~kg} / \mathrm{m}^{3}$, of lead was $11,340 \mathrm{~kg} / \mathrm{m}^{3}$, and of iron was $7,874 \mathrm{~kg} / \mathrm{m}^{3}$; the density of water was $1000 \mathrm{~kg} / \mathrm{m}^{3}$. It was assumed that since the settling tank would be housed indoors but without any climate control, the temperature during the settling process would be $4.4^{\circ} \mathrm{C}$.

The viscosity of liquids decreases with increasing temperature. The relationship between temperature and viscosity is expressed as an Arrhenius equation as follows:

$$
\mu=\mu_{o} \frac{E_{\mu}}{e^{R T}},
$$

where $\mu_{o}$ is the viscosity at a reference temperature $\left(4.4^{\circ} \mathrm{C}\right)$, $E_{\mu}$ is the temperature coefficient for viscosity, $R$ is the gas constant, and $T$ is the temperature in Kelvin. Therefore, the dynamic viscosity was $0.001519 \mathrm{~kg} / \mathrm{m}$-s at the specified temperature of $4.4^{\circ} \mathrm{C}$. The viscosity of wash water based on the above equation ranged from $0.00091 \mathrm{~kg} / \mathrm{m}$-s to $0.00179 \mathrm{~kg} / \mathrm{m}$ $\mathrm{s}$ as the temperature was varied from $0^{\circ} \mathrm{C}$ to $21.1^{\circ} \mathrm{C}$. The density of water also varied as the temperature changed from $0^{\circ} \mathrm{C}$ to $21.1^{\circ} \mathrm{C}$ with values ranging between $998 \mathrm{~kg} / \mathrm{m}^{3}$ and $1,000 \mathrm{~kg} / \mathrm{m}^{3}$.

2.5. Analytical Methods. The heavy metals selected for washwater analysis were aluminum (Al), arsenic (As), boron (B), beryllium (Be), cadmium (Cd), cobalt (Co), chromium $(\mathrm{Cr})$, copper $(\mathrm{Cu})$, iron $(\mathrm{Fe})$, lithium $(\mathrm{Li})$, manganese $(\mathrm{Mn})$, molybdenum (Mo), nickel $(\mathrm{Ni})$, lead $(\mathrm{Pb})$, selenium $(\mathrm{Se})$, vanadium $(\mathrm{V})$, and zinc $(\mathrm{Zn})$. Each sample was placed in $1 \mathrm{~L}$ high density polyethylene bottle; $125 \mathrm{~mL}$ of the sample was preserved with $(1+1)$ reagent grade nitric acid at $\mathrm{pH}$ $<2$. The rest of the sample was left unpreserved. $25 \mathrm{~mL}$ of the sample was preserved with $(1+1)$ reagent grade nitric acid at $\mathrm{pH}<2$ and then filtered with a $5 \mu \mathrm{m}$ filter. The preserved samples were digested according to EPA 200.7 and analyzed by Inductively Coupled Plasma-Optical Emission Spectrometry (ICP-OES) that used an Agilent 720/730 series spectrometer. ICP-OES can be used to determine dissolved analytes in aqueous samples after suitable filtration and acid preservation. For the determination of total recoverable analytes in aqueous and solid samples, digestion/extraction is required prior to analysis. The traffic metals were analyzed 
for their total concentration as well for the dissolved metal concentrations. The calibration, detection limits, and linear ranges were determined according to EPA 200.7. Dissolved analytes were filtered with a $0.45 \mu \mathrm{m}$ filter before analysis through ICP-OES. Unpreserved samples were analyzed for the following: conductivity (HACH CO150 Conductivity Meter), pH (Fisher Scientific AB15 pH Meter), and total dissolved solids (Shimadzu TOC-5000A TOC Analyzer).

\section{Results and Discussion}

3.1. Pilot Unit Heavy Metal Removal. This section characterizes the attributes of the wash water from Stark County garage, which was the location that all the wash water was collected from throughout the duration of the study. In order to characterize the wash water, a 3-hour wash study was performed at the Stark County garage. In characterizing the wash water, the traffic metals of concern in this study were highlighted. Analysis of any observable trends in heavy metal concentrations during the 3-hour sampling duration was made and any probable causes were discussed. Finally, in the characterization, the nonmetal attributes of the wash water were quantified. The heavy metal removal efficiency from the wash water by the pilot unit was then analyzed. This was accomplished through analyzing the removal mechanisms in two distinct stages. The first stage of the analysis was the physical removal of any particulate species greater than the $5 \mu \mathrm{m}$ size. The second stage of the analysis was the removal of any species less than $5 \mu \mathrm{m}$ in size including not only metals in the dissolved phase but also metals in the particulate form less than $5 \mu \mathrm{m}$ in size. Although three experimental trials were run on the filtration unit, trial Stark 1 was not studied extensively because the dissolved constituent (below $5 \mu \mathrm{m}$ ) of the heavy metal concentrations of the wash water was frequently below the detection limit. The percentage of copper samples below the detection limit was $83 \%$ with the percentage of lead samples below the detection limit at 35\%. This meant that observations of any significant changes in dissolved heavy metal concentrations through treatment by the MAR Sorbster media could not be made. Trials Stark 2 and Stark 3 had a measurable dissolved metal concentration range that allowed for observations of trends through the different filtration unit locations, although monitoring was carried out only for two of the heavy metals, zinc and iron.

3.2. Wash-Water Characteristics. Table 1 represents the total metal concentrations during the 3-hour study with the traffic heavy metals of concern highlighted for ease of identification. The traffic heavy metals of concern were observed during a study of water quality parameters of wash water taken during wash cycles at 24 ODOT garages during the winter of 2012-2013. Of all samples tested, 59\% were above the reuse limitations for total copper and $66 \%$ were found to be above in total zinc [4]. Considering both metal concentrations, only $28 \%$ of all samples were found to be reusable according to the Ohio Administrative Code (OAC) aquatic, agricultural, and wildlife standards based on the characteristic hardness of receiving water bodies. The variability of the metals in Table 1 was observed, which can be accounted for by several

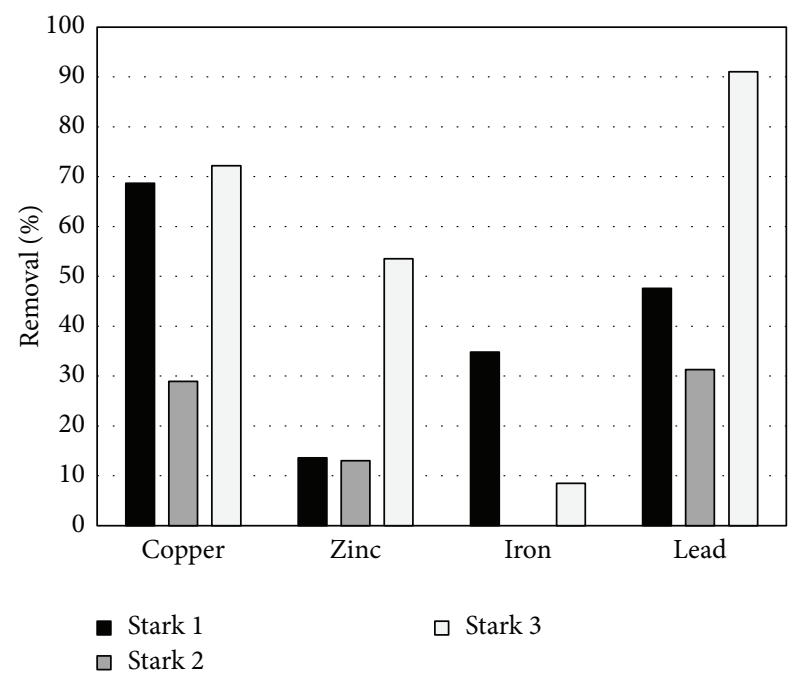

Figure 1: Total metal removal due to the $5 \mu \mathrm{m}$ filter located directly after the inlet of the filtration unit. Removal percentage was calculated based on the average concentration after the $5 \mu \mathrm{m}$ filter across all time periods. Refer to Table 2 .

factors based on the conditions of the wash including varying hose pressure during the wash as well as any initial flushes towards the beginning of the wash. Another possible cause for the variation in metal concentrations during the 3-hour study could be attributed to inconsistent depths at which the samples were collected. The nonmetal parameters were also characterized with the characteristic $\mathrm{pH}$ of the wash water between 6.5 and 7. The conductivity of the wash water was on average $73.9 \mathrm{mS} / \mathrm{cm}$. The turbidity of the wash water was on average 42,788 NTU.

3.3. Filtration Unit Heavy Metals Removal by Filters. A portion of the total metal removal is attributed to the $5 \mu \mathrm{m}$ filters only which are located immediately after the inlet of the pilot unit and directly before the vessels containing the MAR Sorbster media. Figure 1 summarizes the removal of each metal for each of the three Stark County filtration unit runs by these initial $5 \mu \mathrm{m}$ filters. The average metal removal of total copper, zinc, iron, and lead by just the $5 \mu \mathrm{m}$ filter is $57 \%, 27 \%, 8 \%$, and $57 \%$, respectively, across all 3 experimental runs. Removal percentages were calculated based on the initial concentrations of the influent wash water which are given in Table 2 and the average metal concentrations after the $5 \mu \mathrm{m}$ filter across all time periods; that is, the metal concentration of every sample taken throughout the duration of each filtration run at the location after the $5 \mu \mathrm{m}$ filter was averaged to attain the removal percentage.

When total metal concentrations are evaluated, a clear and consistent pattern is observed for the three pilot unit runs from the Stark County garage. Figures 1 and 2 display the cumulative removal of copper and zinc as the wash water passes through each stage in the pilot unit. The removal percentage for each location was calculated based on the average concentration across all time periods tested at that location. A similar pattern is found for iron and lead. After treatment 


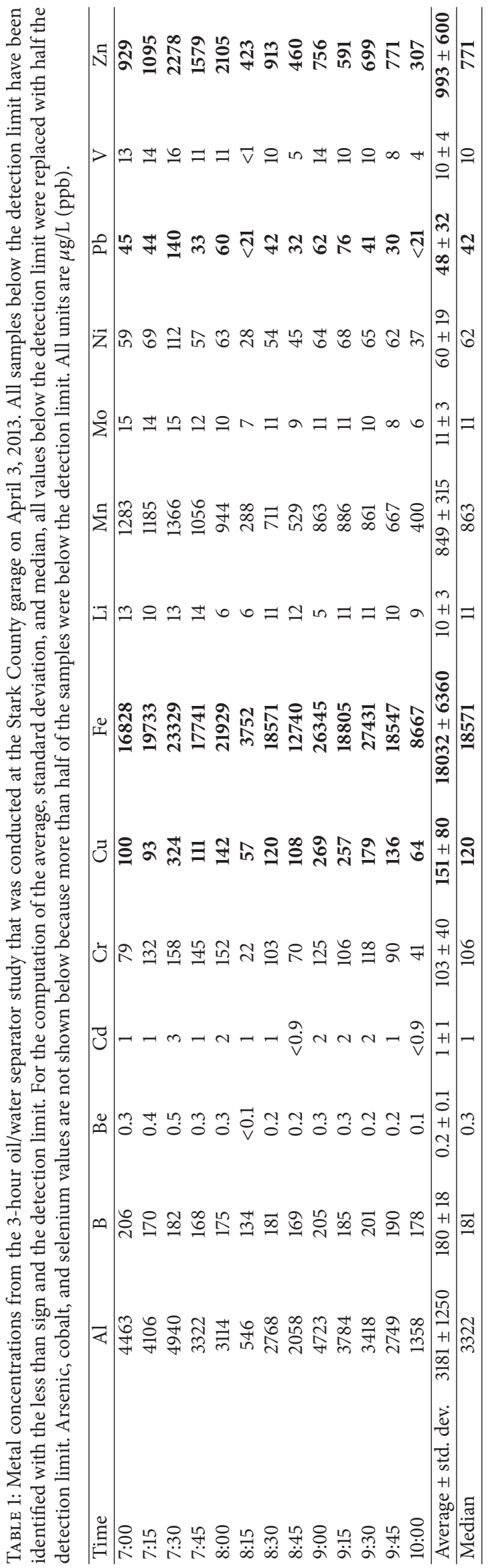


TABLE 2: Initial total metal concentrations for experimental runs Stark 1, Stark 2, and Stark 3 measured at the inlet of the filtration unit. All samples below the detection limit were given the value of half the detection limit. Only the traffic metals that are of concern regarding the violation of reuse and disposal guidelines are listed. All units are $\mu \mathrm{g} / \mathrm{L}(\mathrm{ppb})$.

\begin{tabular}{lccc}
\hline Heavy metal species & \multicolumn{3}{c}{ Experimental run } \\
& Stark 1 & Stark 2 & Stark 3 \\
\hline Copper & 197 & 277 & 236 \\
Iron & 8033 & 2667 & 2684 \\
Lead & 23 & 747 & 364 \\
Zinc & 564 & 827 & 690 \\
\hline
\end{tabular}

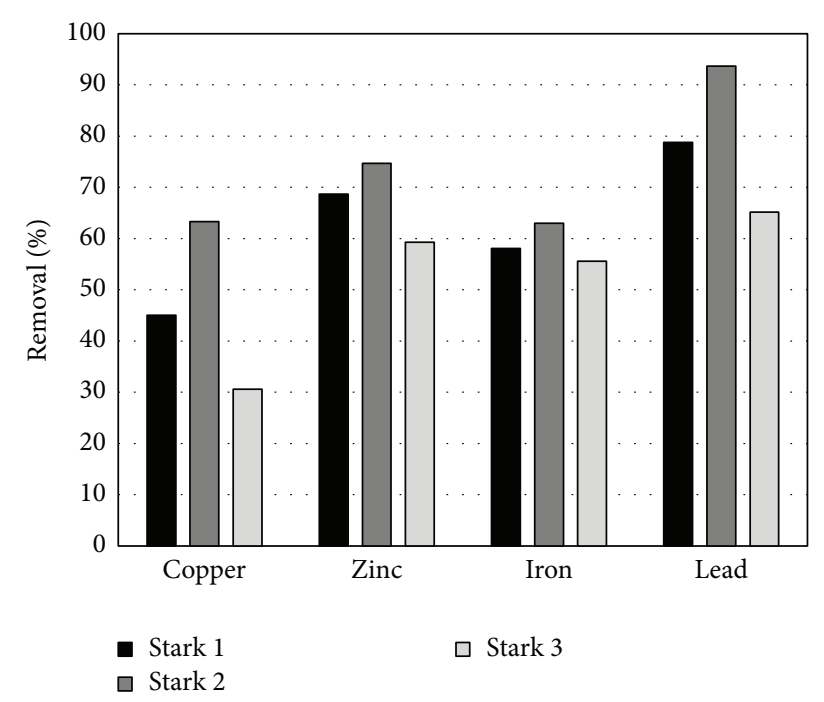

FIgURe 2: Percent removal of total metals by MAR media on all metals less than $5 \mu \mathrm{m}$ in diameter, that is, the percent removal of total metals in the vessels of the filtration unit by the MAR media. Removal percentage was calculated based on the average concentration after vessel 2 for all time periods and the average concentration after the $5 \mu \mathrm{m}$ filter for all time periods.

with the pilot unit, the average total copper removal for all three experiments was $79 \%$. For total zinc, the average removal is $77 \%$. For total iron, the average removal is $63 \%$. For total lead, the average removal is $94 \%$. For the influent concentration, an initial sample was taken at the beginning of each trial and used throughout the trial; therefore, there was no resampling of the influent concentration at the different time periods. This was done in order to maintain a baseline with which to analyze heavy metal removal across the time periods and locations.

Analyzing Figure 1 which illustrates the heavy metal removal percentages by the $5 \mu \mathrm{m}$ filter located immediately after the inlet of the filtration unit and directly before the media vessels, there is relatively high heavy metal removal by the $5 \mu \mathrm{m}$ filters. What can also be observed as well is that, for the metals of concern, copper and zinc, a significantly higher average percentage, $57 \%$, of copper was removed by the $5 \mu \mathrm{m}$ filters as compared to $27 \%$ removal of zinc. This may be indicative of the notion that higher toxicity of copper is in

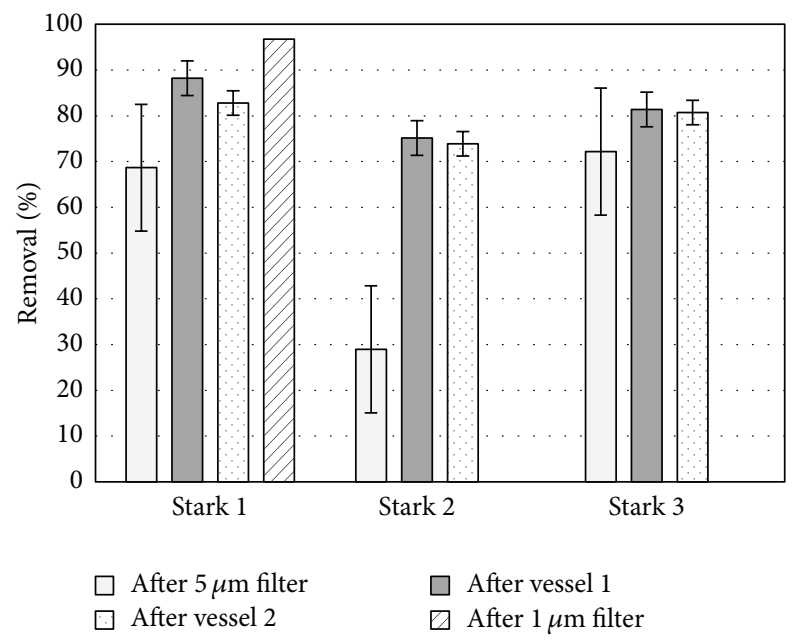

FIgURE 3: Cumulative removal of total copper at each stage of the Stark County garage trials. The removal percentage for each location was calculated based on the average concentration across all time periods tested at that location. The second and third trials did not have the optional $1 \mu \mathrm{m}$ filter attached at the end of the unit. The error bars are indicative of the standard error.

the particulate form, whereas zinc toxicity is predominantly characterized by particles less than $5 \mu \mathrm{m}$ in size.

3.4. Filtration Unit Heavy Metals Removal by MAR Media. After the $5 \mu \mathrm{m}$ filter, the reduction in the metal concentrations is attributed solely to MAR Systems Sorbster media. As exhibited in Figure 2, the media within vessels 1 and 2 remove between $30 \%$ and $94 \%$ of metal particles less than $5 \mu \mathrm{m}$ depending on the experimental run and the type of metal. For copper, average metal removal of $46 \%$ is found for particles less than $5 \mu \mathrm{m}$. For zinc, the removal percentage is even better at $68 \%$. For iron and lead, the removal percentages are $59 \%$ and $79 \%$, respectively. Removal percentages were calculated based on the average concentration after vessel 2 for all time periods and the average concentration after the $5 \mu \mathrm{m}$ filter for all time periods.

For trial Stark 2, the concentration of dissolved zinc was reduced from an initial concentration of $88 \mu \mathrm{g} / \mathrm{L}$ to $15 \mu \mathrm{g} / \mathrm{L}$. For trial Stark 3, the trend was similar as the dissolved zinc concentration was reduced from $78 \mu \mathrm{g} / \mathrm{L}$ to $6 \mu \mathrm{g} / \mathrm{L}$. For trial Stark 2, the dissolved iron concentration increased from $110 \mu \mathrm{g} / \mathrm{L}$ to $288 \mu \mathrm{g} / \mathrm{L}$. For trial Stark 3, the dissolved iron concentration increased from $148 \mu \mathrm{g} / \mathrm{L}$ to $235 \mu \mathrm{g} / \mathrm{L}$. The increase of the dissolved iron could be attributed to the makeup of the MAR Sorbster media. Sorbster media however are effective in dissolved zinc removal. Analyzing Figure 2, the metal removal by the Sorbster media is greater for zinc at $68 \%$ than it is for the other metal of concern, copper, at $46 \%$. This solidifies what is shown in Figure 1 that the dominant constituent form of zinc contributing to its toxicity is dissolved and particulate below the $5 \mu \mathrm{m}$ size fraction whereas copper is found in greater concentrations in the particulate (greater than $5 \mu \mathrm{m}$ ) size fraction. Figures 3 and 4 can further illustrate removal trends by isolating each of the metals of concern and 
TABLE 3: Percent total metal removal by a $4 \mu \mathrm{m}$ and $5 \mu \mathrm{m}$ filter for each of the six wash-water samples.

\begin{tabular}{lccccccc}
\hline \multirow{2}{*}{ County garage } & \multicolumn{2}{c}{ Copper } & \multicolumn{2}{c}{ Zinc } & \multicolumn{2}{c}{ Iron } & \multicolumn{2}{c}{ Lead } \\
& $>5 \mu \mathrm{m}$ & $>4 \mu \mathrm{m}$ & $>5 \mu \mathrm{m}$ & $>4 \mu \mathrm{m}$ & $>5 \mu \mathrm{m}$ & $>4 \mu \mathrm{m}$ & $>5 \mu \mathrm{m}$ \\
\hline Allen & 98 & 99 & 82 & 86 & 94 & 95 & 96 \\
Stark 1 & 98 & 98 & 93 & 95 & 99 & 98 & 100 \\
Stark 2 & 82 & 73 & 72 & 84 & 98 & 99 & 96 \\
Fairfield & 40 & 46 & 25 & 28 & 87 & 96 & 93 \\
Guernsey & 99 & 99 & 81 & 82 & 99 & 99 & 93 \\
Cuyahoga & 72 & 73 & 9 & 10 & 44 & 43 & 99 \\
\hline
\end{tabular}

See (2).

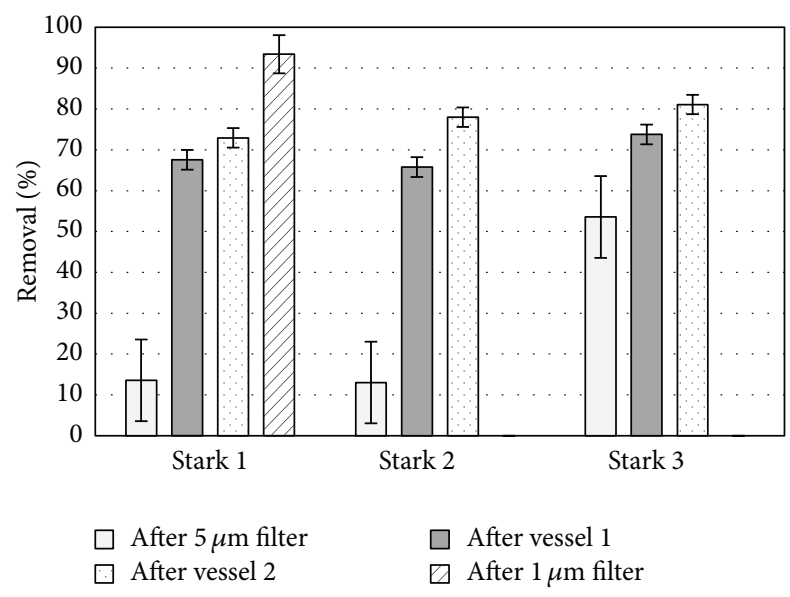

FIGURE 4: Cumulative removal of total zinc at each stage of the Stark County garage trials. The removal percentage for each location was calculated based on the average concentration across all time periods tested at that location. The second and third trials did not have the optional $1 \mu \mathrm{m}$ filter attached at the end of the unit. The error bars are indicative of the standard error.

assessing the metal removal rate at each stage of the filtration unit. Analyzing copper in Figure 3, for each of the experimental trials, there was initial physical metal removal by the $5 \mu \mathrm{m}$ filters on the filtration unit. There was a continued increase in the cumulative removal rate of copper from the wash water through vessel 1 which contained the Sorbster media, which indicated that both physical removal of particulates below the $5 \mu \mathrm{m}$ size and adsorption of dissolved copper by the Sorbster media were the mechanisms of removal. After vessel 1 , the cumulative copper removal did not continue to increase but it statistically did not change from vessel 1 to vessel 2 .

This, as observed earlier, indicates that, of the two forms in which copper was found in the wash water, the particulate (greater than $5 \mu \mathrm{m}$ ) form contributes more to the toxicity of copper in wash water. In contrast, analyzing Figure 4 particularly trials Stark 1 and Stark 2, although there was removal of zinc by the $5 \mu \mathrm{m}$ filters, the majority of the removal was observed after the wash water was treated in vessel 1 with an average increase in the cumulative removal in excess of $50 \%$. There was a continued increase in the cumulative removal through vessel 2 as well. This showed that the Sorbster media were the primary mode of removal for zinc, further indicating that the zinc in the wash water was most toxic in particle sizes below the $5 \mu \mathrm{m}$ size.

3.5. Particle Settling Heavy Metal Removal Evaluation. The result of effect of the size of particles on heavy metal toxicity was then further explored through a size gradation experiment. Wash water for the size gradation experiment was collected from five garages distributed across the state of Ohio. The selection criteria for each garage were dependent on whether the traffic metals of concern in this study exceeded reuse limits at that particular garage. If a garage exceeded the reuse limits, it becomes a candidate for selection for the gradation experiment which graded the wash water in three distinct size gradations. After this, results of the analysis of settling times for the particle sizes with significant contributions towards heavy metal toxicity are discussed. Settling depths typical of settling basin depths at Ohio Department of Transport garages were used in the analysis and varying temperature ranges were used to mimic different garage conditions and settings. Finally, any beneficial applications and implementation methods are discussed.

This section analyzes the results of the particle size evaluation procedure that was conducted. Table 3 summarizes the percentage total metal removal by the $4 \mu \mathrm{m}$ and $5 \mu \mathrm{m}$ Whatman filter paper particle size evaluation procedure. For copper, the average removal by the $4 \mu \mathrm{m}$ filter was $81 \%$ while that of the $5 \mu \mathrm{m}$ filter was $82 \%$. For zinc, the average removal by the $4 \mu \mathrm{m}$ filter was $64 \%$ while that of the $5 \mu \mathrm{m}$ filter was $60 \%$. For iron, the average removal by the $4 \mu \mathrm{m}$ filter was $89 \%$ while that of the $5 \mu \mathrm{m}$ filter was $87 \%$. For lead, the average removal by the $4 \mu \mathrm{m}$ filter was $76 \%$ while that of the $5 \mu \mathrm{m}$ filter was $76 \%$. This indicates that there is a significant portion of the total metal concentration that is present in the particulate form greater than $4 \mu \mathrm{m}$. Looking at the $5 \mu \mathrm{m}$ and $4 \mu \mathrm{m}$ sizes overall average total metal removal also indicates that there is not much difference in total metal removal between the two size fractions. Again, it can be observed that for the two metals of concern copper is more predominantly toxic in the particle size range greater than the $5 \mu \mathrm{m}$ size. Although the reduction in zinc toxicity was reduced by $60 \%$, there is still a significant metal concentration of zinc in the dissolved phase and particulate form below the $5 \mu \mathrm{m}$ size fraction. Using this, along with the clogging of filters due to particulate metals, the merit of allowing the wash water to settle in order to allow for removal of colloidal metals became a viable and efficient 
TABLE 4: Summarization of settling times for the significant particle sizes of copper and zinc for depths most similar to settling tanks located at ODOT garages $(2 \mathrm{~m}-3 \mathrm{~m})$. Times are computed using Stokes law and the dynamic viscosity of water is assumed to be $0.001519 \mathrm{~kg} / \mathrm{m}-\mathrm{s}\left(4.4^{\circ} \mathrm{C}\right)$. Settling times are in hours.

\begin{tabular}{lccccc}
\hline Metal & \multicolumn{2}{c}{$5 \mu \mathrm{m}$} & \multicolumn{2}{c}{$3 \mu \mathrm{m}$} \\
& $2 \mathrm{~m}$ & $3 \mathrm{~m}$ & $2 \mathrm{~m}$ & $3 \mathrm{~m}$ \\
\hline Copper & 7.8 & 11.7 & 21.6 & 32.4 \\
Zinc & 10.1 & 15.1 & 28.0 & 42.0 \\
\hline
\end{tabular}

option to reduce total metal concentrations worthy of further study.

Settling calculations were conducted at depths ranging from 0 meters to depths of 3 meters with major emphasis put on the depth ranges of 2 meters- 3 meters which is characteristic of ODOT settling basins and tanks. The significance of this is that at this depth ODOT garages capacity to work on a day-to-day basis would not be jeopardized by overfilling or overflow due to multiple wash events before any existing wash water is allowed to settle. The summary of the settling of copper is shown in Table 4. The size fractions analyzed were $1 \mu \mathrm{m}-5 \mu \mathrm{m}$. The settling times for $1 \mu \mathrm{m}$ size fraction ranged from 97.3 hours to 486.3 hours with the depth increasing from $1 \mathrm{~m}$ to $5 \mathrm{~m}$, whereas the settling times for the $5 \mu \mathrm{m}$ size ranged from 3.9 hours to 19.5 hours with the depth increasing from $1 \mathrm{~m}$ to $5 \mathrm{~m}$. The settling times were varied by depth. For the $1 \mu \mathrm{m}$ size fraction of zinc, the settling times ranged from 126.1 hours to 630.5 hours as the depth increased from $1 \mathrm{~m}$ to $5 \mathrm{~m}$. For the $5 \mu \mathrm{m}$ size fraction of zinc, the settling times ranged from 5.0 hours to 25.2 hours as the depth increased from $1 \mathrm{~m}$ to $5 \mathrm{~m}$. The $1 \mu \mathrm{m}$ size fraction of lead had settling times that varied from 74.9 hours to 374.4 hours as the depth increased from $1 \mathrm{~m}$ to $5 \mathrm{~m}$; the $5 \mu \mathrm{m}$ size fraction of lead varied from 3.0 hours to 15.0 hours as the depth increased from $1 \mathrm{~m}$ to $5 \mathrm{~m}$. The $1 \mu \mathrm{m}$ size fraction of iron had settling times that varied from 112.6 hours to 563.1 hours as the depth increased from $1 \mathrm{~m}$ to $5 \mathrm{~m}$; the $5 \mu \mathrm{m}$ size fraction of iron varied from 4.5 hours to 22.5 hours as the depth increased from $1 \mathrm{~m}$ to $5 \mathrm{~m}$. Table 4 shows the settling times for copper and zinc for depths of $2 \mathrm{~m}$ and $3 \mathrm{~m}$ for the size fractions $3 \mu \mathrm{m}$ and $5 \mu \mathrm{m}$. Figure 5 illustrates the settling time for the zinc particle at a fixed temperature of $4.4^{\circ} \mathrm{C}$ which is typical of a housed settling basin during the winter months at ODOT garages. Zinc was chosen because it is the metal with the smallest density among the metals of concern; therefore, all the other metals would take a shorter time frame to settle than zinc, thus making the overall critical settling time depend more on the critical zinc settling times.

Figure 6 shows the settling times for copper, iron, and lead at the same temperature of $4.4^{\circ} \mathrm{C}$ at depths ranging from $0 \mathrm{~m}$ to $3 \mathrm{~m}$. The temperature of the water has a great effect on the settling time as well. In order to grasp what the effect was, the settling times based on temperatures ranging from $0^{\circ} \mathrm{C}$ to $21.1^{\circ} \mathrm{C}$ were plotted against depths ranging from $0 \mathrm{~m}$ to $3 \mathrm{~m}$. This temperature range was chosen as it represented the different extreme conditions that a settling basin would be subjected to if it were located indoors or outdoors during

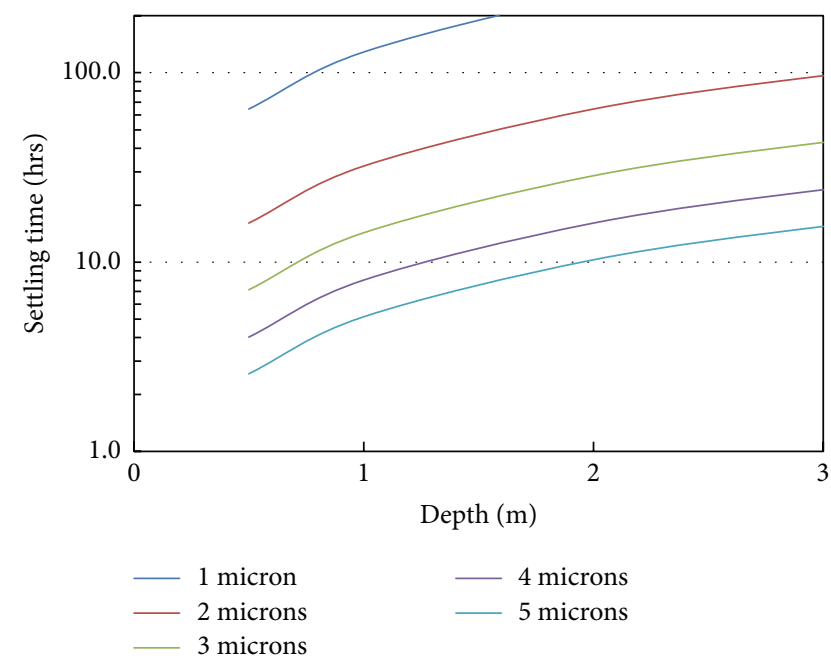

FIGURE 5: Settling times for zinc particles based on Stokes law. The assumed dynamic viscosity of water for the equation is $0.001519 \mathrm{~kg} / \mathrm{m}$-s $\left(4.4^{\circ} \mathrm{C}\right)$. The settling times vary by depth with the different size fraction.

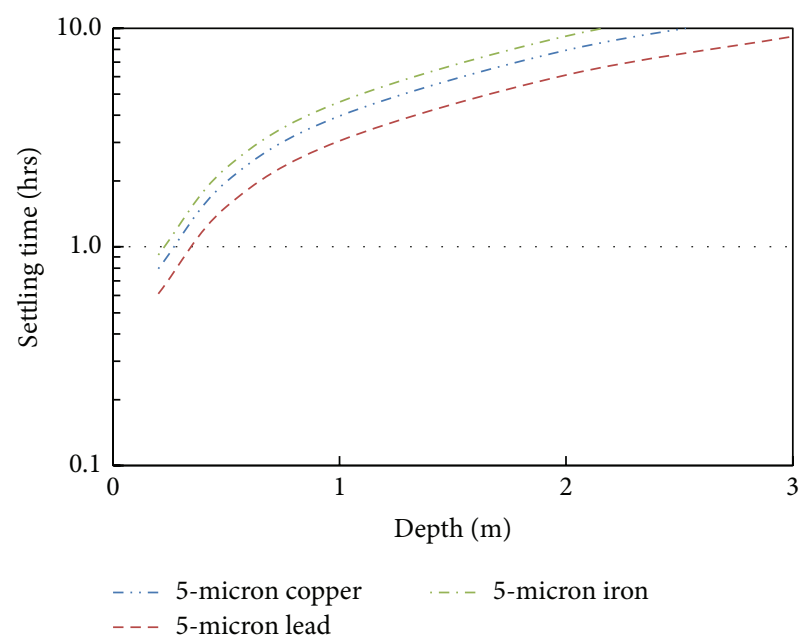

FIGURE 6: Settling time for copper, iron, and lead particles based on Stokes law. The assumed dynamic viscosity of water for the equation is $0.001519 \mathrm{~kg} / \mathrm{m}-\mathrm{s}\left(4.4^{\circ} \mathrm{C}\right)$. The settling times vary by depth, size, and material.

the winter months when winter maintenance was conducted. This is illustrated by both Figure 7 and Table 5 . Both show that, for instance, keeping the depth fixed at $2 \mathrm{~m}$ and a temperature of $0^{\circ} \mathrm{C}$ and a temperature of $5^{\circ} \mathrm{C}$, the resultant settling time difference was 2 hours. These subtle changes can help improve treatment times of wash water through settling by finding an optimal temperature at which to allow the wash water to settle.

3.6. Application and Implementation. Owing to the variability in the heavy metal constituents of the winter maintenance wash water used throughout the duration of this study, recommendations for a single treatment train for winter maintenance wash water cannot be made with any confidence. It has been shown that the form (particulate or 


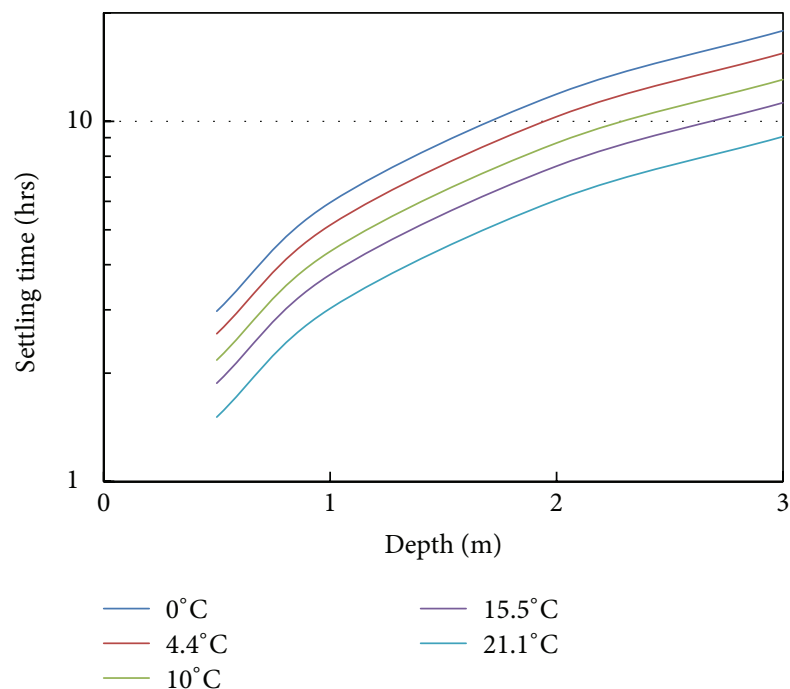

Figure 7: Settling times for zinc particles based on Stokes law. The assumed dynamic viscosity of water for the equation is determined based on the temperature of the water. The settling times vary by the different water temperatures and the depth to which particles are settling.

TABle 5: Settling times in hours for zinc particles based on Stokes law. The assumed dynamic viscosity of water for the Stokes law equation is determined by the temperature of the water. The particle settling times vary based on water temperature and the depth to which the particles are settling.

\begin{tabular}{lccccc}
\hline \multirow{2}{*}{ Depth $(\mathrm{m})$} & \multicolumn{5}{c}{ Temperature $\left({ }^{\circ} \mathrm{C}\right)$} \\
& 0 & 5 & 10 & 16 & 21 \\
\hline 1 & 6 & 5 & 4 & 4 & 3 \\
2 & 12 & 10 & 9 & 8 & 6 \\
3 & 18 & 15 & 13 & 11 & 9 \\
\hline
\end{tabular}

dissolved) or particle size range in which the heavy metal is most toxic would allow a choice of either media filtration or settling. By retrofitting an ODOT garage with both settling tanks and a filtrations unit, the majority of the particulate metals can be removed through allowing the wash water to sit for a prescribed period of time, before running the wash water through the filtration system to remove any remaining particulates and the majority of the dissolved constituent as well. The study has shown that MAR Sorbster media are effective in reducing heavy metals concentration in wash water. The study also showed that, allowing the wash water to settle for a prescribed amount of time at an optimal temperature, the majority of the particulate constituent of heavy metals can be eliminated and, for heavy metal species that are more toxic in larger particle size ranges, this can be a viable treatment option if used in isolation. Understanding the nature of the wash water allows for a more appropriate treatment regime to be applied.

\section{Conclusions}

The study assessed the heavy traffic metal reduction in winter maintenance wash water by MAR Sorbster media as well as the impact of particle size on heavy metal concentration. A pilot unit filled with the media was used to run a series of continuous flow experiments to assess heavy metal removal on winter maintenance wash water. The wash water was taken from ODOT's Stark County garage in Northeast Ohio. The total and dissolved metal concentrations were assessed. The metals assessed were copper, zinc, lead, and iron. The effect of particle size on heavy metal toxicity was analyzed and theoretical settling calculations using Stokes law were applied to assess viable heavy metal removal mechanisms. The following conclusions can be drawn:

(i) Particulate metal concentrations are typically higher than dissolved metal concentrations for the traffic metals.

(ii) The pilot unit removal efficiency for copper and zinc removal in the wash water exceeded $70 \%$ of the influent concentration.

(iii) The $5 \mu \mathrm{m}$ filters removal efficiency for copper exceeded $25 \%$, for zinc exceeded $10 \%$, and for lead exceeded $30 \%$.

(iv) For all the trials, MAR Sorbster media average removal efficiency for copper exceeded $30 \%$, for zinc exceeded $55 \%$, for lead exceeded $50 \%$, and for iron exceeded $60 \%$ for particles $<5 \mu \mathrm{m}$.

(v) Of the two heavy metals of concern, copper was found predominantly more in the particulate form, and this contributed a greater percentage of the overall toxicity of copper. Zinc alternatively was found to be in the dissolved phase and particulates below the $5 \mu \mathrm{m}$ size range.

(vi) Allowing the wash water to settle for a minimum of 10 hours would allow removal of particulates larger than $5 \mu \mathrm{m}$ resulting in heavy metals removal rates exceeding $70 \%$. In addition, adjusting the temperature to an optimal temperature can reduce settling times in excess of a few hours based on settling depths.

(vii) Overall MAR Sorbster media are an effective option to remove heavy metals in winter maintenance wash water, particularly zinc whose cumulative removal increased in excess of $50 \%$ by the end of treatment by just a single filtration media vessel.

(viii) Alternatively, allowing the wash water to settle results in a significant reduction in heavy metal concentration in winter maintenance wash water which was equal to or close to the filtration pilot heavy metal reduction.

\section{Competing Interests}

The authors declare that they have no competing interests.

\section{References}

[1] Ohio Department of Transportation, Snow and Ice Practices, Division of Operations, Office of Maintenance Administration, 2011. 
[2] J. E. Alleman, B. K. Partridge, and L. Yeung, "Innovative environmental management of winter salt runoff problems at INDOT maintenance yards," 2004.

[3] V. Craver, G. Fitch, and J. Smith, "Recycling of saltcontaminated stormwater runoff for brine production at Virginia Department of Transportation Road-Salt Storage Facilities," Tech. Rep. VTRC 08-R17, Virginia Transportation Research Council, Charlottesville, Va, USA, 2008.

[4] C. M. Miller, W. H. Schneider IV, M. Kennedy, H. Parker, and S. Sullivan, "Snow removal waste water disposal alternatives," State Job PS-2012-06, Ohio Department of Transportation, Office of Research and Development, Columbus, Ohio, USA, 2012.

[5] Q. Zhou, J. Zhang, J. Fu, J. Shi, and G. Jiang, "Biomonitoring: an appealing tool for assessment of metal pollution in the aquatic ecosystem," Analytica Chimica Acta, vol. 606, no. 2, pp. 135-150, 2008.

[6] A. Dong, G. Chesters, and G. V. Simsiman, "Metal composition of soil, sediments, and urban dust and dirt samples from the Menomonee River Watershed, Wisconsin, USA," Water, Air, and Soil Pollution, vol. 22, no. 3, pp. 257-275, 1984.

[7] W. G. Wilber and J. V. Hunter, "Distribution of metals in street sweepings, stormwater solids, and urban aquatic sediments," Journal of the Water Pollution Control Federation, vol. 51, no. 12, pp. 2810-2822, 1979.

[8] J. J. Sansalone and S. G. Buchberger, "Partitioning and first flush of metals in urban roadway storm water," Journal of Environmental Engineering, vol. 123, no. 2, pp. 134-143, 1997.

[9] E. Smolders and F. Degryse, "Fate and effect of zinc from tire debris in soil," Environmental Science and Technology, vol. 36, no. 17, pp. 3706-3710, 2002.

[10] N. Fukuzaki, T. Yanaka, and Y. Urushiyama, "Effects of studded tires on roadside airborne dust pollution in Niigata, Japan," Atmospheric Environment, vol. 20, no. 2, pp. 377-386, 1986.

[11] J. Sternbeck, Å. Sjödin, and K. Andréasson, "Metal emissions from road traffic and the influence of resuspension-results from two tunnel studies," Atmospheric Environment, vol. 36, no. 30, pp. 4735-4744, 2002.

[12] A. P. Davis, M. Shokouhian, and S. Ni, "Loading estimates of lead, copper, cadmium, and zinc in urban runoff from specific sources," Chemosphere, vol. 44, no. 5, pp. 997-1009, 2001.

[13] E. J. Christensen, C. E. Olney, and T. F. Bidleman, "Comparison of dry and wet surfaces for collecting organochlorine dry deposition," Bulletin of Environmental Contamination and Toxicology, vol. 23, no. 1, pp. 196-202, 1979.

[14] B. A. Bodo, "Heavy metals in water and suspended particulates from an urban basin impacting Lake Ontario," Science of The Total Environment, vol. 87-88, pp. 329-344, 1989.

[15] J. Liebens, "Heavy metal contamination of sediments in stormwater management systems: the effect of land use, particle size, and age," Environmental Geology, vol. 41, no. 3-4, pp. 341351, 2002.

[16] M. Ujevic and P. S. Letelier, "Acceleration, streamlines and potential flows in general relativity: analytical and numerical results," Classical and Quantum Gravity, vol. 18, no. 15, p. 2917, 2001.

[17] M. C. Andral, S. Roger, M. Montréjaud-Vignoles, and L. Herremans, "Particle size distribution and hydrodynamic characteristics of solid matter carried by runoff from motorways," Water Environment Research, vol. 71, no. 4, pp. 398-407, 1999.
[18] B. Kus, M. Johir, J. Kandasamy et al., "Performance of granular medium filtration and membrane filtration in treating stormwater for harvesting and reuse," Desalination and Water Treatment, vol. 45, no. 1-3, pp. 120-127, 2012.

[19] J. Q. Jiang and B. Lloyd, "Progress in the development and use of ferrate(VI) salt as an oxidant and coagulant for water and wastewater treatment," Water Research, vol. 36, no. 6, pp. 13971408, 2002.

[20] S. Dastgheibi, Stormwater treatment using in-ground permeable reactive filter systems: batch test evaluation of media [Ph.D. dissertation], University of Illinois at Chicago, Chicago, Ill, USA, 2012.

[21] K. R. Reddy, T. Xie, and S. Dastgheibi, "PAHs removal from urban storm water runoff by different filter materials," Journal of Hazardous, Toxic, and Radioactive Waste, vol. 18, no. 2, Article ID 04014008, 2014. 

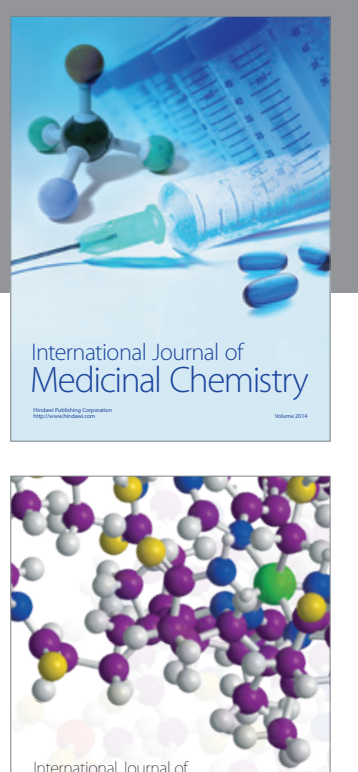

Carbohydrate Chemistry

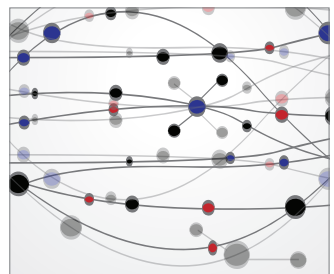

The Scientific World Journal
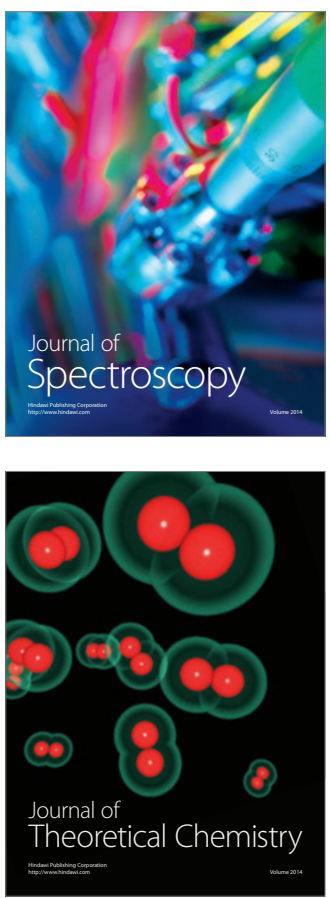
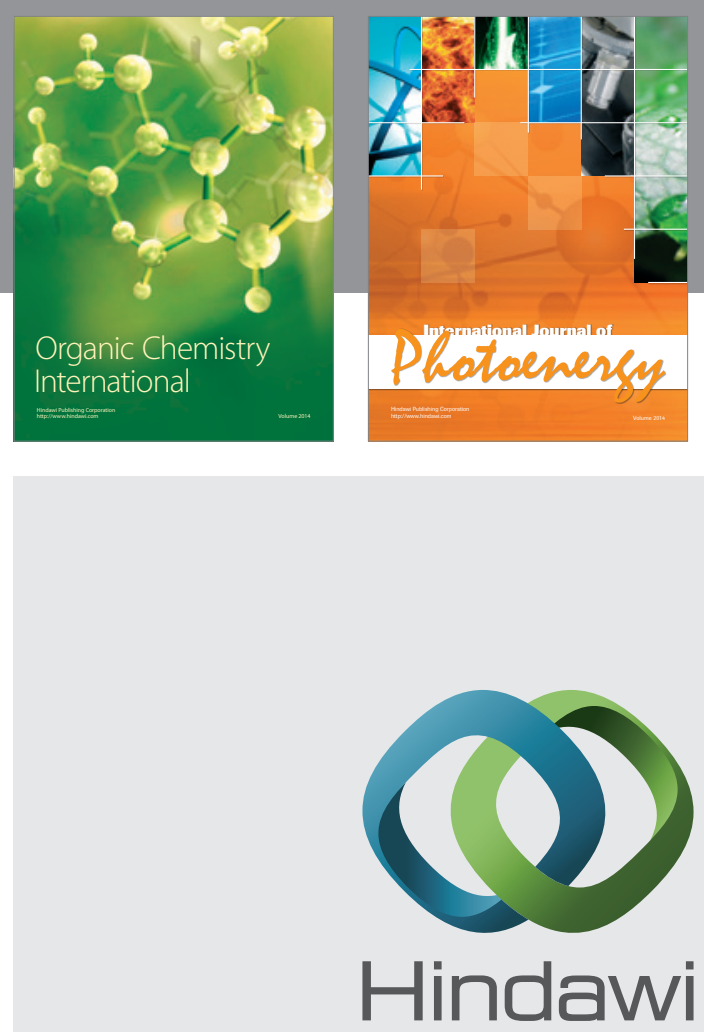

Submit your manuscripts at

http://www.hindawi.com

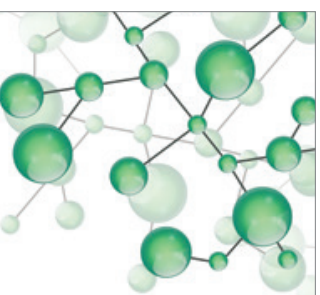

International Journal of

Inorganic Chemistry

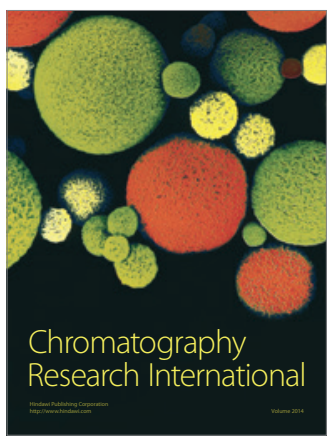

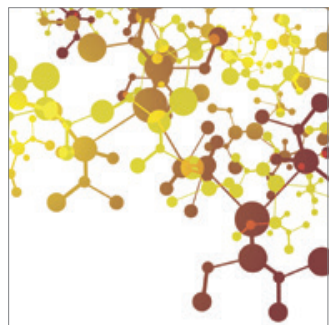

Applied Chemistry
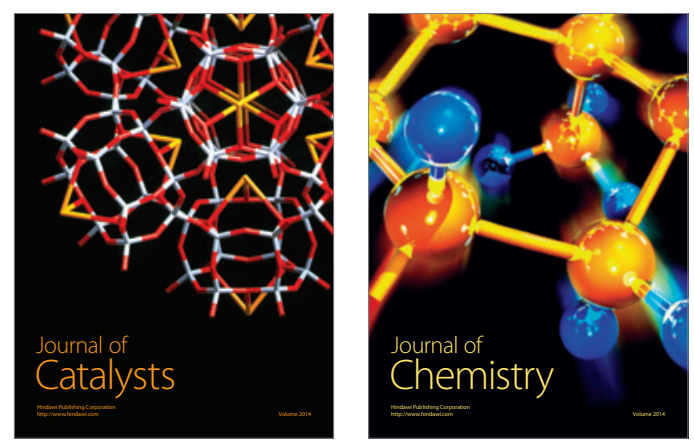
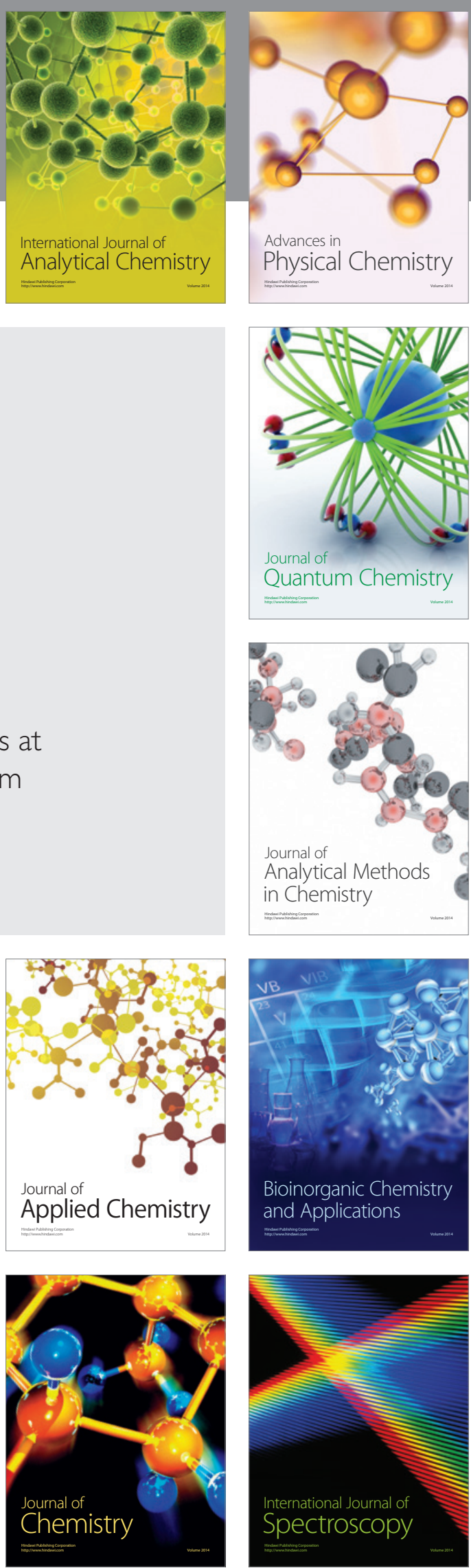